\title{
Experimental Study on Wear Performance and Oil Film Characteristics of Surface Textured Cylinder Liner in Marine Diesel Engine
}

Zhi-Wei Guo ${ }^{1,2}$ (1), Cheng-Qing Yuan ${ }^{1,2^{*}}$, Xiu-Qin Bai ${ }^{1,2}$ and Xin-Ping Yan ${ }^{1,2}$

\begin{abstract}
It is of a vital importance to reduce the frictional losses in marine diesel engines. Advanced surface textures have provided an effective solution to friction performance of rubbing pairs due to the rapid development of surface engineering techniques. However, the mechanisms through which textured patterns and texturing methods prove beneficial remains unclear. To address this issue, the tribological system of the cylinder liner-piston ring (CLPR) is investigated in this work. Two types of surface textures (Micro concave, Micro V-groove) are processed on the cylinder specimen using different processing methods. Comparative study on the friction coefficients, worn surface texture features and oil film characteristics are performed. The results demonstrate that the processing method of surface texture affect the performance of the CLPR pairs under the specific testing conditions. In addition the micro V-groove processed by CNCPM is more favorable for improving the wear performances at the low load, while the micro-concave processed by CE is more favorable for improving the wear performances at the high load. These findings are in helping to understand the effect of surface texture on wear performance of CLPR.
\end{abstract}

Keywords: Cylinder liner-piston ring (CLPR), Surface texture structure, Frictional and wear characteristic, Oil film characteristic

\section{Introduction}

The marine diesel engine is the heart of a marine system. Cylinder liner-piston ring (CLPR) system is one of the major contributors for the mechanical losses in a diesel engine [1]. Surface texture of the cylinder liner is identified as one of the significant factors that improve the tribological properties of diesel engine with regard to wear (surface topography and running performance), oil consumption, fuel efficiency, lubrication oil (element concentration and wear particle), and so on [2]. For this reason, cylinder liner surfaces are processed by exercising immense attention. Many researches focus on the potential of using surface texturing on cylinder liners to improve the friction, wear, lubrication and reduce the friction, and designs of different geometric shapes and

\footnotetext{
*Correspondence: ycq@whut.edu.cn

${ }^{1}$ Reliability Engineering Institute, National Engineering Research Center for Water Transportation Safety, Wuhan 430063, China

Full list of author information is available at the end of the article
}

texturing parameters are investigated using numerical simulation and experimental methods $[3,4]$.

Through the early studies, Akamatsu et al. [5] found that the surface concave can improve the life of the friction pairs operating in mixed/boundary lubrication regimes. Later on, various models including the numerical $[6,7]$, lubrication [8], and analytical $[9,10]$ ones were developed to study and reduce the friction between cylinder liner and piston ring by alternating the shape, size, and pattern orientations of the surface textures.

For the experiments, various surface texturing methods [11-18] employed by the researchers. Such as laser surface texturing $[11,12]$, pulsed air arc treatment [13], electropolishing [14], reactive ion etching (RIE) [15], photochemical machining [16], maskless electrochemical texturing [17], micro computer numerical control (CNC) texturing [18], and so on. Among the different surface texturing techniques, laser texturing technique is one of the most widely used thermal energy based noncontact type advanced method. Etsion and Sher 
[19] evaluated the effect of partially laser surface-textured piston rings through testing the fuel consumption and exhaust gas composition of a diesel engine. Hua et al. [12] investigated the effect of discriminating partition laser surface micro-texturing on engine comprehensive performance compared the fuel consumption. Yousfi et al. [20, 21] found the effect of surface smoothness and plateauness and theirs evolution during running-in tests. Then, they showed that ellipse patterns oriented at ring sliding direction contribute the most to reduce the friction coefficient using a reciprocating ring-liner tribometer. Grabon et al. [22] compared the tribological behavior of honed cylinder liners with and without additional oil pockets created by burnishing method using reciprocating tester.

In the above existing works of CLPR, the various textured patterns were tested and compared. It seems that texture can lead to friction reduction and/or reducing the fuel consumption. However, the mechanisms through which textured patterns and texturing methods prove beneficial remains unclear. This is in part to the fact that the majority of research focused on comparing the performance of the different textured patterns using the same texturing method, with few texturing methods of same pattern and oil film characteristic being attempted.

Up to date, limited quantity studies on the effect of the surface textures of cylinder liners with assistance of comparing the different texturing methods for better understanding of wear mechanisms and lubrication performances. In addition, only a limited number of texture studies have used test rigs to measure and analyze the oil film characteristic response [23]. Of particular significance is this work carried out by Costa and Hutchings [24] who investigated the influence of surface topography on lubricant film thickness for the reciprocating sliding of patterned plane steel surfaces against cylindrical counter bodies under conditions of hydrodynamic lubrication.

It is well known that the lubricant film characteristic between cylinder liner and piston ring provides a key comparable parameter to evaluate the performance of CLPR. Various methods have been implemented to measure the oil film thickness [25]. Dearlove et al. [26] simultaneously measured mid-stroke lubricant film thickness using the Laser Induced Fluorescence (LIF) and friction force in a single piston ring-floating liner. Mills et al. [27] applied the technique of Ultrasonic Sensing in IC engine cylinder liner applications by mounting elements to the cylinder liner. Other methods such as capacitative [28], induction [29] also have been used to measure the oil film thickness between cylinder liner and piston ring. But each measurement technology has its strengths and weaknesses.
In conclusion, mainly due to the difficulty in performing such measurements under the running conditions of CLPR. As a result, there remain uncertainties regarding the mechanisms by which texturing method or surface texture effect the friction pairs of CLPR. Contact resistance is an effective technique for representing the oil film characteristic of CLPR friction pair. This work aimed to study the influence mechanism of cylinder liner surface texture on the friction and lubrication performance of CLPR components. A series of experiments have been carried out on a reciprocating test rig. The oil film characteristics between cylinder liner and piston ring were obtained using the contact resistance technology. Findings of this work contribute to understanding of the influence of the texturing method and surface micro processing on the CLPR pair and can be referred to in practice.

\section{Experiment and Methodology}

\subsection{Test Sample Preparation}

In order to simulate the CLPR more realistic during the experimental tests, Specimens were cut from cylinder liner and piston ring, which material was typically applied in marine diesel engines. The specimen of cylinder liner was cut from boron cast iron cylinder liner (Figure 1(a)), the specimen of piston ring was cut from ductile cast iron piston ring (Figure 1(b)) and the CLPR mating graph (Figure 1(c)). The metrical parameters of the specimens were displayed in Table 1. Computer Numerical Control (CNC) Wire-Cut Electric Discharge Machining (EDM) was applied to process the specimens.

In the experimental tests, the micro-concave cylinder liner and micro V-groove cylinder liner were prepared using different texturing methods. The selection of the geometries was based on existing work $[1,2,8$, $22]$ in which a dimpled surface was reported to reduce friction although the influences of different processing methods and mixed micro-groove structures were not take into account. The computer numerical control precision machining (CNCPM) was employed to produce the texted surface textures including the microconcave and micro V-groove. Meanwhile, the micro concave was obtained using the chemical etching (CE).

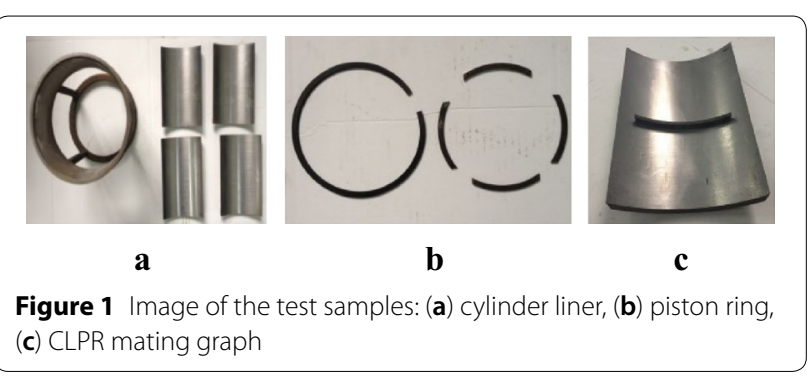


Table 1 Metrical parameters of the specimens

\begin{tabular}{lll}
\hline Parameter & Cylinder liner & Piston ring \\
\hline Material & Boron cast iron & Ductile cast iron \\
Brinell hardness (HB) & $200-240$ & $445-480$ \\
Specimen size & $120 \times 80 \times 10$ & $50 \times 3 \times 5$ \\
$\begin{array}{l}\text { Length } \times \text { Width } \times \text { Thickness } \\
(\mathrm{mm} \times \mathrm{mm} \times \mathrm{mm})\end{array}$ & \\
\hline
\end{tabular}

Table 2 The geometric models and processing parameters of textured cylinder liners

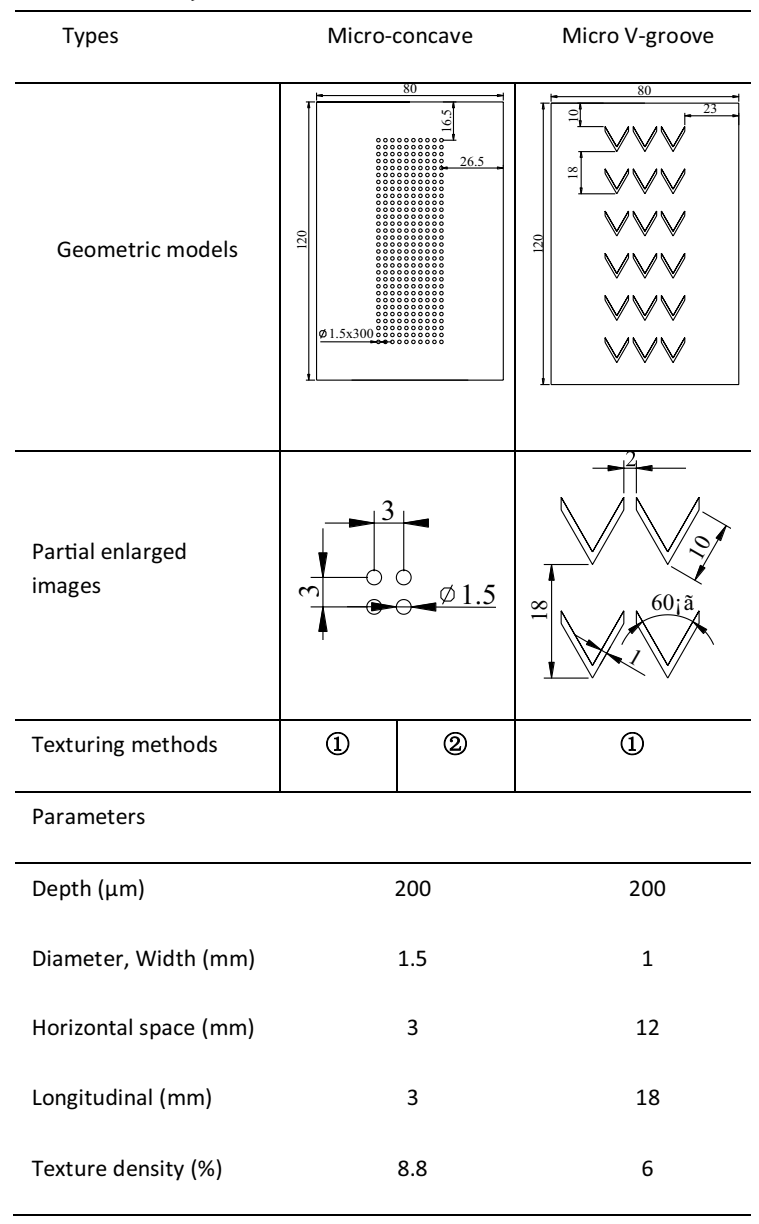

Note: (1) CNCPM; (2) CE

And the parameters of micro-concave by the chemical etching were consistent with that The CNC Precision Machining. The geometric models and processing parameters of textured cylinder liners were shown in Table 2. The piston ring running profile was flat. Compared the different processing method, the hardness of wear surfaces processed by $C E$ became lower than that of CNCPM.

\subsection{Experimental Apparatus and Wear Tests}

All wear experiments were conducted using a commercial reciprocating wear testing machine (MWF10 tribo-tester, Yihua Ltd., China). The sketch map of the reciprocation tester is shown in Figure 2. During the tests, the upper specimen (made of piston ring) remained stationary while the lower specimen (made of cylinder liner) slid against the surface of the upper specimen with a reciprocation motion. The required load was pressed on the upper specimen. The rotational movement was changed into reciprocating movement by a crankshaft assembly. The radius of crank was $50 \mathrm{~mm}$, therefore its stroke was $100 \mathrm{~mm}$.

To accelerate the tribo-tests to obtain the results in a reasonable time frame, special lubricating oil without additives was used in this study. The $70 \mathrm{~N}$ based oil with a kinematic viscosity of $13 \mathrm{~mm}^{2} / \mathrm{s}$ at $40{ }^{\circ} \mathrm{C}$ was used. The tribological tests were carried out under full lubrication. Lubricating fluid was supplied into the inlet side of the contact zone, while the frequency of lubrication was $1 \mathrm{~mL} / \mathrm{min}$; during the test time interval between oil drops delivery was the same.

In order to simulate the real applications in marine diesel engine, friction test were conducted at a stable low speed $200 \mathrm{r} / \mathrm{min}$. Experiment was performed with three average loads: $200 \mathrm{~N}, 400 \mathrm{~N}, 600 \mathrm{~N}$. Each CLPR friction pair ran for $4 \mathrm{~h}$. All friction tests were repeated twice under the same condition to check the repeatability of the results. After completion of each experiment, the fixtures of cylinder liner and piston ring were cleaned to ensure that each CLPR ran in the same condition.

\subsection{Measurement Techniques}

The quantitative studies of the wear properties and features were conducted through friction coefficient analysis, topographical analysis of worn surface, composition examination, and oil film characteristic. Brief information of these techniques used in this work is provided below.

The results of friction force measurement were recorded using laboratory measuring system. The topographies of the prepared sample surfaces were measured using a 3D surface profilometer before and after the tests. The tip radius of the stylus was $2 \mu \mathrm{m}$. The previous version of this test method was described in details in Ref. [2].

According to the features of the cylinder liner surfaces, the four surface height-related parameters were adopted to describe the distinct between the different surface textured cylinder liners. The definitions of the selected parameters are presented as follows. 


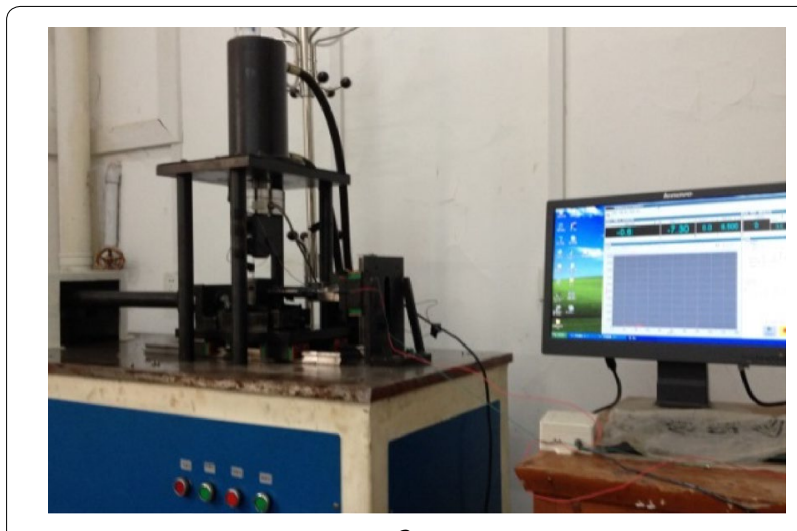

$\mathbf{a}$

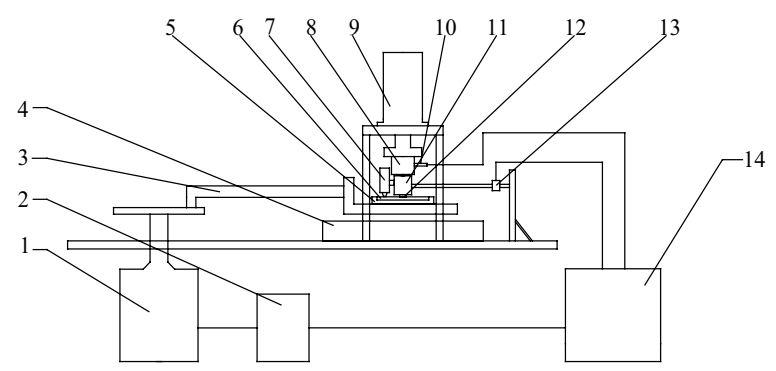

b

Figure 2 Reciprocation tester: (a) picture of the tester; (b) schematic diagram. 1. Electromotor, 2. Frequency transformer, 3. Link mechanism, 4. Guide rail, 5. Fixture of cylinder liner, 6. Specimen of cylinder liner, 7. Digital microscope, 8. Loading device, 9. Hydraulic system, 10. Sensor of load force, 11. Fixture of piston ring, 12. Specimen of piston ring, 13. Sensor of friction force, 14. Industrial personal computer

The root mean square $\left(S_{\mathrm{q}}\right)$ is amplitude parameter and is defined as [30]:

$$
S_{\mathrm{q}}=\sqrt{\frac{1}{M N} \sum_{0}^{M-1} \sum_{0}^{N-1}\left(Z\left(x_{k}, y_{l}\right)-u\right)^{2}} .
$$

The root mean square gradient $\left(S_{\mathrm{dq}}\right)$ is the hybrid parameters indicated the RMS-value of the surface slope within the sampling area, and is defined as [30]:

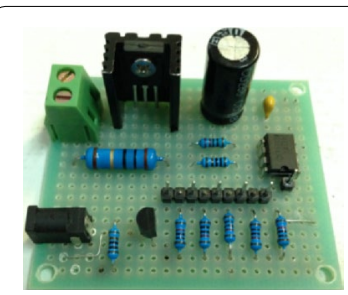

$\mathbf{a}$

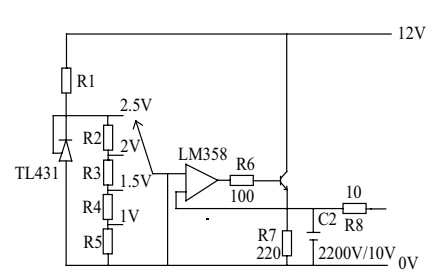

b
Figure 3 Contact resistance tester system: (a) appearance; (b) schematic diagram

$$
S_{\mathrm{vi}}=\frac{V_{v}\left(h_{0.05}\right)-V_{v}\left(h_{0.8}\right)}{(M-1)(N-1) \delta_{x} \delta_{y}} / S_{q}
$$

where $Z\left(x_{k}, y_{l}\right)$ is the height value for $\left(x_{k}, y_{l}\right), M$ is the sampling points for the direction of $x$, and $N$ is the sampling points for direction $y$.

Contact resistance analysis technique was used to characterize the lubrication oil film thickness and examine the wear severities between the cylinder liner and piston ring. The circuit and schematic diagrams were shown in Figure 3. Electrical conductivity of the lubricating oil has a great disparity with that of the metal was the operating principle of this method. This technique requires an insulated surface mounted sensor of the contact elements. In this study, two wires were respectively attached to the specimen of cylinder liner and piston ring. Meanwhile, the specimens of cylinder liner and piston ring were insulated with their fixtures using the fish paper. The electrical resistances of the friction pair were recorded by the Labview acquisition system and analyzed to determine the lubrication oil film characteristics of the friction pairs and their wear mechanisms.

\section{Results and Discussion}

The tribological properties of the CLPR were investigated through comparative analyses of the friction coefficients, wear surface topographies and resistances values under

$$
S_{\mathrm{dq}}=\sqrt{\frac{1}{(M-1)(N-1)} \sum_{k=0}^{M-1} \sum_{l=0}^{N-1}\left(\frac{z\left(x_{k}, y_{l}\right)-z\left(x_{k-1}, y_{l}\right)}{\delta x}\right)^{2}+\left(\frac{z\left(x_{k}, y_{l}\right)-z\left(x_{k}, y_{l}-1\right)}{\delta y}\right)^{2}} .
$$

The surface bearing index $\left(S_{\mathrm{bi}}\right)$ and valley fluid retention Index $\left(S_{\mathrm{vi}}\right)$ are the functional parameters, and is defined as [30]:

$$
S_{\mathrm{bi}}=\frac{S_{q}}{Z_{0.05}}
$$

different surface textures, texturing methods and running conditions. The results are presented in the following sections. 


\subsection{Analysis of Friction Coefficients}

Table 3 shows the variation of friction coefficient of the CLPR friction pairs at different surface textures, texturing methods and loads under the same rotational speed $(200 \mathrm{r} / \mathrm{min})$. Different surface textures and texturing methods produced a significant effect on the friction coefficients of CLPR friction pairs.

With the increase of load, the growth trend of the friction coefficient in the micro-concave processed by CE was firstly increased and then decreased, while in the micro-concave and the micro $\mathrm{V}$-groove processed by the CNCPM were gradually increased. This probably that either the texturing methods or the surface textures had a certain influence on the friction properties of the CLPR friction pairs. We discuss the influence details as followings.

\subsubsection{Friction Coefficients under Different Texturing Methods} It was well known that the surface concave could improve the wear properties of the friction pair [1, 7] and various surface texturing methods were employed by researchers to process the surface of friction pairs [31]. However, little research was focused on the effect of the texturing methods in understanding the wear mechanisms and lubrication performances.

As can be seen in Table 3, the friction coefficients in the CNCPM textured cylinder liner was smaller than that in the CE textured cylinder liner at the low loads $(200 \mathrm{~N}$ and $400 \mathrm{~N})$ while at the high load $(600 \mathrm{~N})$, the opposite is true.

Table 3 Variation of friction coefficients for the textured cylinder liners

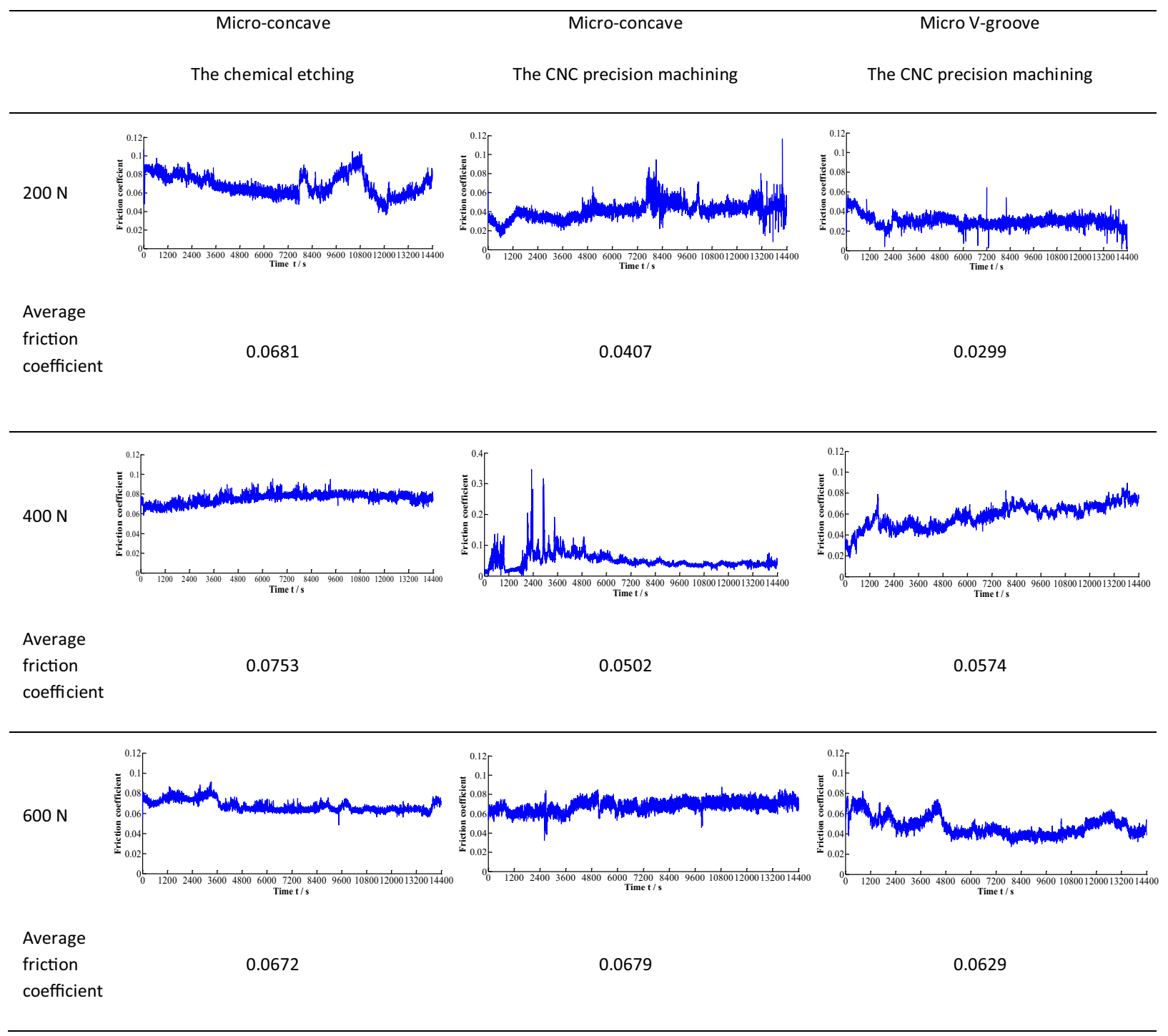


It was hypothesized that the CNCPM texturing method was better for cylinder liner than CE texturing method at the low loads. Moreover, at the low loads (200 N and $400 \mathrm{~N}$ ), the mean values of friction coefficients with the CNCPM surface were 0.0407 and 0.0502 , while the CE surface were 0.0681 and 0.0753 . It was mainly because the processing methods changed the surface contact performance. The surface hardness under different texturing methods was measured using an automatic digital display Rockwell hard-tester (Huayin Ltd., China). The hardness of the untreated cylinder liner surface was 19.4 HRC, while the CE surface was $17.6 \mathrm{HRC}$ and the CNCPM surface was 20.9 HRC. During the processing of $\mathrm{CE}$, the hardness of wear surface became low, the normal forces loaded by hydraulic system were remained constant during the tests, so the soft surface processed by $\mathrm{CE}$ needed longer testing time to remove and the wear degree became more severe at low loads than that of the CNCPM. Consequently, the CE method may produce larger friction coefficients than the CNCPM. Because the friction force became larger during remove the effected surface of cylinder liners. But with the high load $(600 \mathrm{~N})$, the effected surface was removed during the beginning of the test, which can be proved by the curve variation tendencies of the first $3600 \mathrm{~s}$ in Table 3 (Micro-concave processed by CE, $600 \mathrm{~N}$ ). As a result, the friction coefficient was firstly raised and then decreased during the loads increased. During the processing of CNCPM, the hardness of wear surface increases due to high processing temperature, so the wear degree became slight at low loads. In addition, the existence of the micro-concave made the cylinder liner surface store a portion of the lubrication oil and improved the lubrication at low loads. With the increase of load, the condition of lubrication became worse. This ultimately increased the friction coefficients between the friction pairs. Finally, it led to a rise in friction coefficients.

\subsubsection{Friction Coefficients under Different Surface Textures}

The types of surface textures influenced the friction coefficient behaviors markedly as shown in Table 3 . The variation of the friction coefficient between cylinder liner and piston ring of the two different types of surface texture processed by CNCPM were compared and analyzed. At the load of $200 \mathrm{~N}$, the friction coefficient in the micro $\mathrm{V}$-groove surface was smaller than that in the microconcave surface. The possible reasons were that when the micro V-groove were ran at a low load, the existence of the grooves made the cylinder liner surface store amount of lubrication oil, which was much more than that in the micro-concave surface. The lubrication oil slowed down the wear of CLPR friction pair. And thus the friction coefficient was relatively low at the load of $200 \mathrm{~N}$. When the applied load increased to $400 \mathrm{~N}$, the friction coefficient in the micro V-groove surface was larger than that in the micro-concave surface. This is because that when the load increased, the wear surfaces of friction pairs were forced into close contact. Due to the fact that the length of the groove was larger than the thickness of piston ring and the diameter of micro-concave was smaller than the thickness of piston ring, the lubrication oil in the micro V-groove was more readily to be squeezed out than the micro-concave. Hence, the friction coefficient of micro $\mathrm{V}$-groove was larger than that of micro-concave at the load of $400 \mathrm{~N}$. When the applied load grew to $600 \mathrm{~N}$, the lubrication environment of CLPT became harshest. A large number and different kinds of wear particles generated. For the micro V-groove cylinder liner, some wear particles were whirled away by the lubrication oil. In addition, the micro $\mathrm{V}$-groove could retain more and larger size of wear particles than the micro-concave. Consequently, the friction coefficient of micro $\mathrm{V}$-groove was lower than that of micro-concave at the load of $600 \mathrm{~N}$.

\subsection{Surface Topographies Analysis of Cylinder Liner Worn Surface}

Table 4 shows the test parameters of the treated surface textures after the tests. Because of friction and wear between the CLPR friction pair, the scratches along the reciprocation direction were left on the specimens during the $4 \mathrm{~h}$ of testing. Moreover, the topographies of the cylinder liner presented a direct relationship with their wear performances. Therefore, the wear mechanism could be characterized by the microscopic parameters of worn surfaces. At a microscopic scale, the lubrication of friction pair was inferred through quantitative topographic studies of the cylinder liner worn surfaces. The parameters were obtained by averaging the measured areas.

According to the $S_{\mathrm{q}}$ values, the distribution of the cylinder liner surface peaks mostly increased after the tests. It was mainly because the wear process along contact surfaces of the cylinder liner destroyed the original topographies and made the height distribution more non-uniform. The $S_{\mathrm{q}}$ values of micro-concave processed by $\mathrm{CE}$ were smaller at low loads and larger at high load than that by the CNCPM, which was consistent with the variation trend of friction coefficient. Using the same processing method, the $S_{\mathrm{q}}$ values of micro-concave were smaller at load of $400 \mathrm{~N}$ and larger at loads of $200 \mathrm{~N}$ and $600 \mathrm{~N}$ than that of micro V-groove.

A high $S_{\mathrm{dq}}$ value may indicate a rapid change in the surface topography and a higher friction and wear between cylinder liner and piston ring. This can be intuitively understood comparing the mean values of different surface textures and different applied loads in Table 4. $S_{\mathrm{bi}}$ is the ratio of the root-mean-square deviation over the 
Table 4 Test parameters of the cylinder liner surface textures after the tests

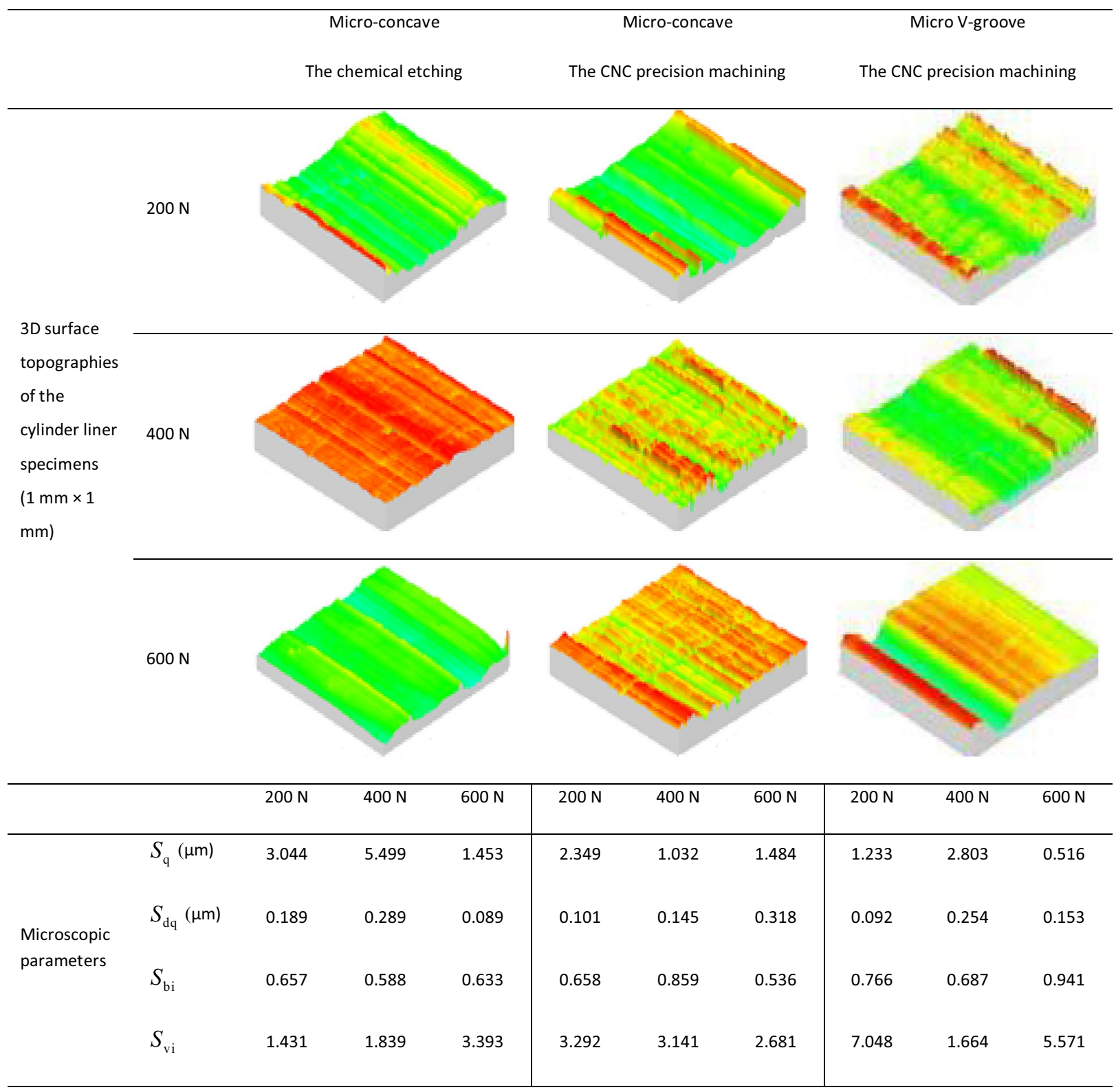

surface height at 5\% bearing area. For a Gaussian height distribution $S_{\mathrm{bi}}$ approaches 0.608 for an increasing number of pixels. A large $S_{\mathrm{bi}}$ indicates a good bearing property. The results produced in this work revealed that the micro V-groove had a highest $S_{\mathrm{bi}}$ value $(>0.608)$ at $200 \mathrm{~N}$ which indicated that it had a good bearing property, micro-concave processed by CE had a smallest $S_{\mathrm{bi}}$ value $(<0.608)$ at $400 \mathrm{~N}$ indicating a poor bearing property, and micro-concave processed by CNCPM had a smallest $S_{\mathrm{bi}}$ value $(<0.608)$ at $600 \mathrm{~N}$ and a highest $S_{\mathrm{bi}}$ value $(>0.608)$ at $400 \mathrm{~N}$. Functional parameter $S_{\mathrm{vi}}$ is used to indicate the fluid retention property in the valley zone. A larger $S_{\mathrm{vi}}$ indicates a good retention capability feature. In this study, the $S_{\mathrm{vi}}$ values had the same tendency as $S_{\mathrm{bi}}$.

Finally, through the comparative analysis of the microscopic parameters of different surface textured cylinder liners, it found that the cylinder liner shown different performance under the different loads and surface textures. The micro-concave cylinder liner processed by $\mathrm{CE}$ was suitable for running with the load $600 \mathrm{~N}$, the micro-concave cylinder liner processed by CNCPM was suitable for running in the applied load $400 \mathrm{~N}$ and the 
micro V-groove cylinder liner processed by CNCPM was suitable for running with the loads $400 \mathrm{~N}$ and $600 \mathrm{~N}$. In general, the micro $\mathrm{V}$-groove processed by CNCPM was better on the wear surface improvement than others during the tests.

\subsection{Analysis of Contact Resistance}

To further analyze the effect of the cylinder liner surface textures and load on the lubrication oil film characteristic, the contact resistance measuring technique was used to calculate the variation and mean values of the contact resistance.

Figure 4 depicts the variation of contact resistance values for the micro-concave cylinder liner processed by $\mathrm{CE}$ and piston ring with different loads. It can be seen that the loads had a significant effect on the contact resistance values of CLPR friction pairs. In general, the contact resistance values were decreased as the load increased. As well known, the loads had a significant effect on the tribological properties of friction pairs. When the load grew, the wear surfaces of the friction pairs were forced into close contact. The thickness of the lubrication oil film between them became thinner.

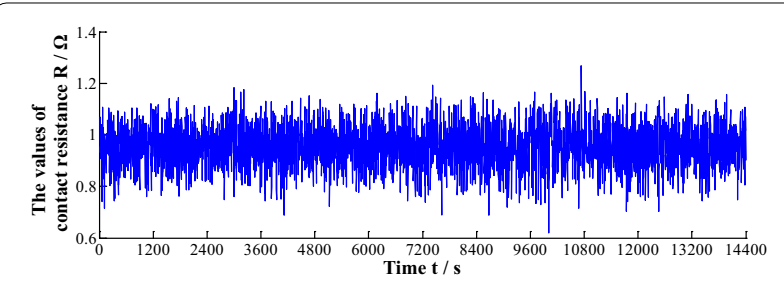

a $200 \mathrm{~N}$
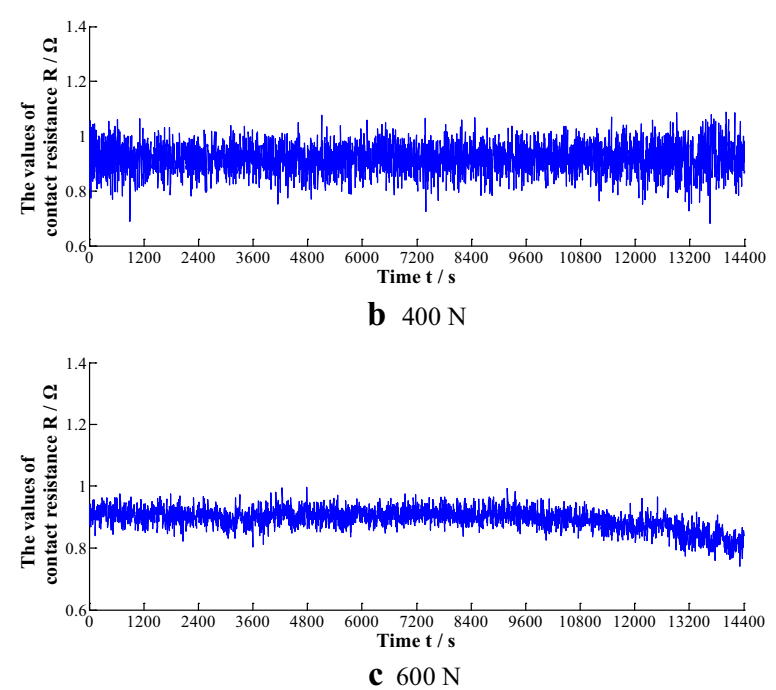

Figure 4 Variation of contact resistance values for the micro-concave cylinder liner processed by CE at the different load: (a) $200 \mathrm{~N}$, (b) $400 \mathrm{~N},(\mathbf{c}) 600 \mathrm{~N}$
Figure 4 also shows that the lubrication oil film between cylinder liner and piston ring can be qualitative characterized by the variation of contact resistance values between them. The cylinder liner and piston ring are mainly composed of metallic materials. Electric will generated by the friction of the CLPR. Since the lubrication oil is weak conductive, if the contact resistance was used to measure the cylinder liner and piston ring during the test, for the same-type of lubrication oil, when the contact resistance value increased, it indicated that the lubrication oil and film thickness between the cylinder liner and piston ring became sufficient and thick and vice versa.

Hence, it can be noticed from Figure 4 that the fluctuation levels of contact resistance values were different when the load increased. The effects of contact resistance values on fluctuation from strong to weak were ranked as $200 \mathrm{~N}, 400 \mathrm{~N}$, and $600 \mathrm{~N}$. The main reason was believed to be as follows. The wear particles were generated from the cylinder liner and piston ring and retained considerable conductivity. So the conductive properties of lubrication oil were affected by the amount and size of the wear particles. At the lowest load, the clearance of the friction pairs was the largest, the wear particles were easily transported to contact area of the friction pairs and the fluctuation level of contact resistance values between the cylinder liner and piston ring was relatively large. When the load grew, the wear surfaces of the friction pairs were forced into close contact. The wear particles were hardly transported to the friction pairs and the fluctuation levels of contact resistance values became relatively small.

Figure 5 shows the mean values of contact resistance for cylinder liner and piston ring at different loads and surface textures. For the same surface texture but different loads, the mean values of contact resistance were decreased as the load increased. Comparison of the

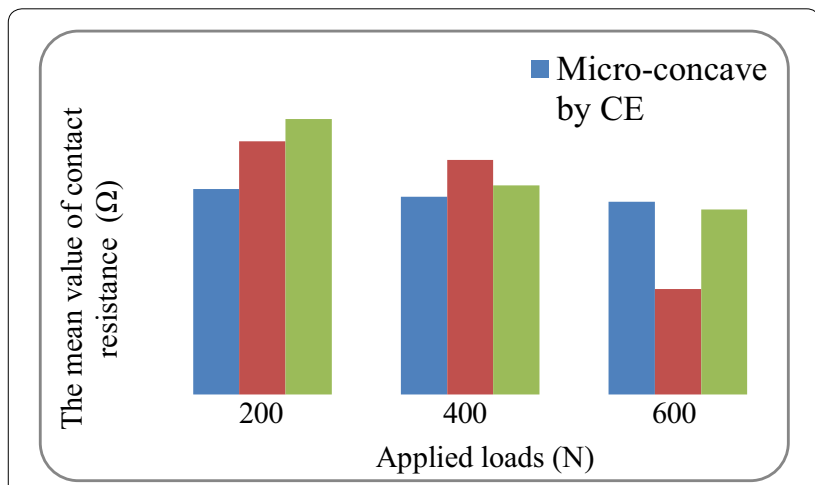

Figure 5 Variation of mean values of contact resistance between cylinder liner and piston ring under different surface textures and applied loads 
mean values of the same load, the mean value of micro $\mathrm{V}$-groove by CNCPM was the largest at $200 \mathrm{~N}$, the mean value of micro-concave by CNCPM was the largest at $400 \mathrm{~N}$ and the mean value of micro-concave by $\mathrm{CE}$ was the largest at $600 \mathrm{~N}$.

The variation of the friction coefficients (in Table 3) and the contact resistance (in Figure 5) under the different loads and surface textures were compared and analyzed. It was found that, the mean value of the friction coefficients in micro V-groove surface at $200 \mathrm{~N}$ was the smallest and the contact resistance was the largest. The results revealed that the mean value of the friction coefficients was in inverse proportion to that of the contact resistance. Inverse growth phenomena appeared only in the micro-concave by $\mathrm{CE}$ at $600 \mathrm{~N}$. The mean value of the friction coefficients was in-between but the contact resistance was the largest. The main reason was believed to be as follows. The surface hardness processed by CE (17.6 HRC) was smaller than that by CNCPM (20.9 $\mathrm{HRC}$ ). The micro-concave processed by CE may provide more lubrication oil between the cylinder liner and piston ring than that by CNCPM under the same load of $600 \mathrm{~N}$. The variance of the mean value of contact resistance for two different types of surface texture processed by CNCPM was larger than that of the friction coefficient. The main reason was that the micro V-groove could retain more wear particles than the micro-concave, so there were more wear particles existed in the lubrication oil between the cylinder liner and piston ring for the micro-concave surface. And the existed wear particles could reduce the value of the contact resistance. These were qualitatively consistent with the trend of the analysis of surface morphologies.

\section{Conclusions}

(1) The wear performances are affected by the texturing methods of surface textures. In addition the micro V-groove processed by CNCPM is more favorable for improving the wear performances at the low load, while the micro-concave processed by $\mathrm{CE}$ is more favorable for improving the wear performances at the high load.

(2) For the different surface textures, the micro $\mathrm{V}$-groove processed by CNCPM is generally better on the wear surface improvement than others during the tested conditions.

(3) The characteristic parameter of contact resistance is firstly used to represent the oil film characteristic and wear performance of surface textured CLPR pair, which is qualitatively consistent with the trend of friction coefficient and surface morphology.
As a whole, the processing method of surface texture affected the performance of the CLPR pairs under the specific testing conditions. Further study is being conducted to analyze the wear performance of different kinds and densities of micro-groove (V-groove, grooves with different angles, and so on) by $\mathrm{CE}$ and the surface textured cylinder liners by other processing method. The outcome will be reported in due course.

\section{Authors' Contributions \\ C-QY was in charge of the whole trial; Z-WG wrote the manuscript; $X-Q B$ and $X-P Y$ assisted with sampling and laboratory analyses. All authors read and approved the final manuscript. \\ Author details \\ ${ }^{1}$ Reliability Engineering Institute, National Engineering Research Center for Water Transportation Safety, Wuhan 430063, China. ${ }^{2}$ Key Laboratory of Marine Power Engineering \& Technology (Ministry of Transport), Wuhan University of Technology, Wuhan 430063, China.}

\section{Authors' Information}

Zhi-Wei Guo, born in 1986, is currently an associate professor at Reliability Engineering Institute, National Engineering Research Center for Water Transportation Safety, Wuhan University of Technology, China. He received his PhD degree from Wuhan University of Technology, China, in 2014. His research interests include the tribology of marine power machinery and surface/interface technology. Tel: +86-27-86554969; E-mail: zwguo@whut.edu.cn.

Cheng-Qing Yuan, born in 1976, is currently a professor, a PhD candidate supervisor and Vice Dean of School of Energy and Power Engineering, Wuhan University of Technology, China. He received his PhD degree from Wuhan University of Technology, China, in 2005. His research interests include the reliability of marine power system, marine tribology and new energy technology of the marine. Tel: +86-27-86582035; E-mail: ycq@whut.edu.cn.

Xiu-Qin Bai, born in 1971, is currently a professor and a PhD candidate supervisor at Reliability Engineering Institute, National Engineering Research Center for Water Transportation Safety, Wuhan University of Technology, China. Her main research interests include marine tribology and ship antifouling \& drag reduction technology. E-mail: xqbai@whut.edu.cn.

Xin-Ping Yan, born in 1959, is currently a professor, a PhD candidate supervisor and the director of National Engineering Research Center for Water Transportation Safety, Wuhan University of Technology, China. His main research interests include tribology, machinery condition monitoring and fault diagnosis, and intelligent transportation system. E-mail:xpyan@whut.edu.cn

\section{Competing Interests}

The authors declare that they have no competing interests.

\section{Funding}

Supported by National Natural Science Foundation of China (Grant No. 51422507), Hubei Provincial Natural Science Foundation of China (Grant No. 2015CFB372), Fundamental Research Funds for the Central Universities of China (Grant No. 2015IVA010), and Tribology Science Fund of State Key Laboratory of Tribology of China (Grant No. SKLTKF14B03).

\section{Publisher's Note}

Springer Nature remains neutral with regard to jurisdictional claims in published maps and institutional affiliations.

Received: 29 June 2016 Accepted: 13 June 2018

Published online: 26 June 2018 


\section{References}

[1] K D Lawrence, B Ramamoorthy. Multi-surface topography targeted plateau honing for the processing of cylinder liner surfaces of automotive engines. Applied Surface Science, 2016, 365(1): 19-30.

[2] ZW Guo, C Q Yuan, P Liu, et al. Study on influence of cylinder liner surface texture on lubrication performance for cylinder liner-piston ring components. Tribology Letters, 2013, 51(1): 9-23.

[3] CX Gu, X H Meng, Y B Xie, et al. Effects of surface texturing on ring/ liner friction under starved lubrication. Tribology International, 2016, 94: 591-605.

[4] C Anderberg, P Pawlus, B G Rosen, et al. Alternative description of roughness for cylinder liner production. Journal of Materials Processing Technology, 2009, 209(4): 1936-1942.

[5] Y Akamatsu, N Tsushiama, T Goto, et al. Influence of surface roughness skewness on rolling contact fatigue life. Tribology Transactions, 1992 35(4): 745-750.

[6] A B Zavos, P G Nikolakopoulos. Simulation of piston ring tribology with surface texturing for internal combustion engines. Lubrication Science, 2015, 27(3): 151-176.

[7] G B Gadeschi, K Backhaus, G Knoll. Numerical analysis of laser-textured piston rings in the hydrodynamic lubrication regime. Journal of Tribology, 2012, 134(4): 041702

[8] B F Yin, X D Li, Y H Fu, et al. Effect of laser textured dimples on the lubrication performance of cylinder liner in diesel engine. Lubrication Science, 2012, 24(7): 293-312.

[9] Y Kligerman, I Etsion, A Shinkarenko. Improving tribological performance of piston rings by partial surface texturing. Journal of Tribology, 2005, 127(3): 632-638.

[10] G Ryk, I Etsion. Testing piston rings with partial laser surface texturing for friction reduction. Wear, 2006, 261(7-8): 792-796.

[11] Y B Gao, B X Wu, Y Zhou, et al. A two-step nanosecond laser surface texturing process with smooth surface finish. Applied Surface Science, 2011, 257(23): 9960-9967.

[12] X J Hua, J G Sun, PY Zhang, et al. Research on discriminating partition laser surface micro-texturing Technology of engine cylinder. Tribology International, 2016, 98: 190-196.

[13] A Moshkovith, V Perfiliev, D Gindin, et al. Surface texturing using pulsed air arc treatment. Wear, 2007, 263: 1467-1469.

[14] T Nakatsuji, A Mori. The tribological effect of electrolytically produced micro-pools and phosphoric compounds on medium carbon steel surfaces in rolling-sliding contact. Tribology Transactions, 2001, 44(2): 173-178.

[15] X L Wang, K Kato. Improving the anti-seizure ability of SiC seal in water with RIE texturing. Tribology Letters, 2003, 14(4): 275-280.

[16] J Y Zhang, Y G Meng. A study of surface texturing of carbon steel by photochemical machining. Journal of Materials Processing Technology, 2012, 212(10): 2133-2140.
[17] J G Parreira, C A Gallo, H L Costa New advances on maskless electrochemical texturing (MECT) for tribological purposes. Surface and Coatings Technology, 2012, 212(212): 1-13.

[18] M H Cho, S Park, Micro CNC surface texturing on polyoxymethylene and its tribological performance in lubricated sliding. Tribology International, 2011, 44(7-8): 859-867

[19] I Etsion, E Sher. Improving fuel efficiency with laser surface textured piston rings. Tribology International, 2009, 42(4): 542-547.

[20] M Yousfin, S Mezghani, I Demiric, et al. Smoothness and plateauness contributions to the running-in friction and wear of stratified helical slide and plateau honed cylinder liners. Wear, 2015, 332-333: 1238-1247.

[21] M Yousfin, S Mezghani, I Demiric, et al. Tribological performances of elliptic and circular texture patterns produced by innovative honing process. Tribology International, 2016, 100: 255-262.

[22] W Grabon, W Koszela, P Pawlu, et al. Improving tribological behaviour of piston ring-cylinder liner frictional pair by liner surface texturing. Tribo/ogy International, 2013, 61(61): 102-108.

[23] S C Vlafescua, S Medinaa. A V Olver, et al. Lubricant film thickness and friction force measurements in a laser surface textured reciprocating line contact simulating the piston ring-liner pairing. Tribology International, 2016, 98: 317-329.

[24] H L Costa, I Hutchings. Hydrodynamic lubrication of textured steel surfaces under reciprocating sliding conditions. Tribology International, 2007 40(8): 1227-1238.

[25] R Mills, J R Vail, J R Dwyer. Ultrasound for the non-invasive measurement of internal combustion engine piston ring oil films. Journal of Engineering Tribology, 2015, 229(2): 207-215

[26] J Dearlove, W K Cheng. Simultaneous piston ring friction and oil film thickness measurements in a reciprocating test rig. SAE Technical Paper, 1995, 104: 1452-1462

[27] R Mills, E R Avan, J Dwyer. Piezoelectric sensors to monitor lubricant film thickness at piston-cylinder contacts in a fired engine. Journal of Engineering Tribology, 2013, 227: 100-111.

[28] S Sochting, I Sherrington. The effect of load and viscosity on the minimum operating oil film thickness of piston-rings in internal combustion engines. Journal of Engineering Tribology, 2009, 223: 383-391.

[29] R Golloch, G Merker, U Kessen, et al. Functional properties of microstructured cylinder liner surfaces for internal combustion engines. Tribotest, 2005, 11(4): 307-324.

[30] ISO. ISO/DIS 25178-2, Geometrical product specification (GPS) — surface texture: Areal-Part2: terms, definitions and surface texture parameters, 2008

[31] U Sudeep, N Tandon, R K Pandey. Performance of lubricated rolling/ sliding concentrated contacts with surface textures: A review. Journal of Tribology, 2015, 137(3): 031501.

\section{Submit your manuscript to a SpringerOpen ${ }^{\circ}$ journal and benefit from:}

- Convenient online submission

- Rigorous peer review

- Open access: articles freely available online

- High visibility within the field

Retaining the copyright to your article

Submit your next manuscript at springeropen.com 